\title{
Projecting Health Outcomes for Portuguese Ageing Population: Challenges and Opportunities
}

\author{
Maria do Rosário Oliveira Martins', Inês Campos Rodrigues ${ }^{2}$, Teresa Ferreira Rodrigues ${ }^{2,3}$ \\ ${ }^{1}$ Unidade de Saúde Pública Internacional e Bioestatística, Instituto de Higiene e Medicina Tropical, \\ Universidade Nova de Lisboa, Lisboa, Portugal \\ ${ }^{2}$ CEPESE - Centro de Estudos da População, Economia e Sociedade, Universidade do Porto, Porto, Portugal \\ ${ }^{3}$ Departamento de Estudos Políticos (DEPol), Faculdade de Ciências Sociais e Humanas, Universidade Nova de \\ Lisboa, Lisboa, Portugal \\ Email: mrfom@ihmt.unl.pt, rodrigues.inesc@gmail.com, trodrigues@fcsh.unl.pt
}

Received 21 May 2014; revised 5 July 2014; accepted 22 July 2014

Copyright (C) 2014 by authors and Scientific Research Publishing Inc.

This work is licensed under the Creative Commons Attribution International License (CC BY).

http://creativecommons.org/licenses/by/4.0/

(c) (i) Open Access

\begin{abstract}
Objectives: To project health outcomes for the period 2011-2031, in the Portuguese population aged 65 years and over, considering the expected changes in its demographic and educational structure. Methods: Demographic projections were produced using the multistate cohort component method. Logistic regression models were fitted to estimate current differences in health outcomes, using data from the Portuguese Health Survey. Such differences were applied to the projection results, in order to project the prevalence of "poor" self-reported health status, functional limitations and disability. Results: Our results point to a future improvement in the considered health outcomes. The prevalence of "poor" self-reported health status, functional limitations and disability will decrease in both genders, but will continue to be higher among women than men. Discussion: Beyond age and gender, other determinants of health, like education, should be considered when studying the possible evolution of health outcomes in an ageing population.
\end{abstract}

\section{Keywords}

Projections, Aging, Educational Level, Self-Reported Health Status, Functional Limitations and Disability

\section{Introduction}

The recent demographic development of the Portuguese population is depicted by a marked change in its age

How to cite this paper: Martins, M.R.O., Rodrigues, I.C. and Rodrigues, T.F. (2014) Projecting Health Outcomes for Portuguese Ageing Population: Challenges and Opportunities. Health, 6, 1874-1882. 
structure, with a clear demographic aging resulting both from decreased levels of fertility and progressive decrease in the mortality levels. The contribution of migration for population growth and renewal has substantially decreased, being now insufficient to ensure an increase in the number of residents in Portugal and to counteract the aging trend, given the diminishing natural increase (Statistics Portugal, Demographic Indicators). As a consequence, the population is increasingly aging: between 1992 and 2011, the number of people aged 65 years and more increased approximately $42 \%$ and, at the end of this period, accounted for $19.1 \%$ of the total population, a value that is clearly above the EU-27 average (17.5\%) and which is only exceeded by Germany (20.6\%), Italy (20.3\%) and Greece (19.3\%) [1].

Demographic ageing is a major challenge with regard to governance decisions, given its inevitable impact on the public policies sector, namely in relation to social support, health care and the labor market [2]. Underlying the global impact of population ageing are the changes in health status that arise from the individual ageing process. Despite the greater susceptibility of the oldest population groups to disease and disability, evidence suggests that such process is modifiable, and that its health consequences are affected not only by the increase in age, but also by a number of social and economic variables that characterize the society and each particular individual [3]. When considering the people aged younger than 85 years, even though an increase in chronic diseases and conditions is being observed in research, trends are showing a postponement in disabilities. This might be partly explained by improvements in detection, diagnosis and treatment of diseases, and similarly by increasing levels of educational attainment and income, improved living and workplace conditions or improved early childhood conditions, among other socio-economic developments [4]. For exceptionally old people (aged older than 85 years), the data are still few and inconsistent.

Among different structural, behavioural and psychosocial factors, age has often been associated to health status. Results from a study about the evolution of self-rated health status in the elderly, by Orfila, F., Ferrer, M., Lamarca, R. and Alonso, J. [5], suggested that, in addition to an increased death probability, age increase is also linked to a greater decline of self-reported health status. However, the same study shows that the association between age and declining health status loses its significance when comorbidities are considered, suggesting that this decline is not due to chronological age in itself. On the other hand, gender differences have been observed with regard to mortality and health status: both incidence and prevalence of disabilities are higher for women at all ages, although mortality is typically higher for men [6]. Finally, education is one of the determinants of health more frequently studied [7]-[10], being included among the more relevant social structural factors, together with gender, income, occupation or marital status [11]. Also, educational level may be considered as the best indicator if lifetime socio-economic status across age and over time: not only does it reflect individual's social position in a comprehensive manner, but it is also the only indicator that is stable after young adulthood, therefore reflecting opportunities to reach a specific socio-economic status better than income and occupational status [12].

Considering the combined influence of gender, age and education on population health, the prospective study of the demographic structure defined by these dimensions may represent an important contribution in order to adjust the health policies and practices to the promotion of a better health status. If, on the one hand, older individuals tend to present a worse health status, compared to the younger, and, on the other hand, those with higher levels of education tend to have a better health status, relatively to the less educated [9] [13]-[15], it is essential to investigate if the effect of education might counterbalance the influence of age increase on health status, when an increasingly aging, but also more educated population is expected.

The objective of this study is to estimate four indicators on health outcomes for the Portuguese population aged 65 years and over, considering the expected changes in population structure by gender, age group and educational attainment. We produced multistate demographic projections for the period 2011-2031 and studied the adjusted impact of education and age on the health outcomes, focusing on self-reported health status and the prevalence of disabilities, using data from the most recent National Health Survey (2005/2006). The following questions were addressed: 1) how will the demographic and educational structure of the Portuguese men and women above 65 years old evolve until 2031? 2) to what extent are there educational differences in self-reported health status, functional limitations and disability within this age group? and 3) what will be the combined effect of the expected changes in the demographic and educational structure of this group, on the prevalence of "poor" self-reported health status, functional limitations and disability? 


\section{Methods}

\subsection{Data Source and Collection}

For producing the demographic projections by gender, age group and educational attainment, data from 2001 and 2011 Census, national projections produced by Statistics Portugal (Instituto Nacional de Estatística (INE), I.P.), the Labour Force Survey (INE, I.P.) and the 2010 Revision of the World Population Prospects (United Nations) were all used, in order to estimate the necessary parameters.

The study of current differences in health status and health services utilization by age and educational level was based on the data from the fourth edition of the National Health Survey (4th NHS), a representative survey of the Portuguese population, planned and conducted by the Statistics Portugal and the National Institute of Health Dr. Ricardo Jorge (INSA), in collaboration with the Directorate-General of Health. The 4th NHS collected information on health status, health determinants, use of health services and sociodemographic characteristics of individuals, being the first edition to cover the entire national territory, including the Autonomous Regions of Azores and Madeira. The questionnaire was administered by direct interview to a representative probability sample of the Portuguese population, between February 2005 and February 2006. The study population included individuals living in family housing units (therefore excluding people living in collective accommodation). Housing unit is a unit of observation commonly used in Census. It is defined as a residence such as a house, apartment, mobile home, or room(s) within a larger structure that provides a space for occupants making up a single household to live and eat. By collective accommodation we mean hotels and similar accommodations and people living together in a unit that is not a family (people institutionalized for example). As a whole, 41,193 individuals living in 15,239 family housing units were interviewed, and the interview completion rate was $76 \%$ nationwide.

\subsection{Measures}

Educational attainment level-The data concerning each individual's highest level of education were categorized into four groups: 1) No education/Primary Education (second cycle of basic education, corresponding to six years of schooling, or less); 2) Lower Secondary Education (nine years of schooling); 3) Upper Secondary Education (twelve years of schooling); and 4) Higher Education (those who achieved, at least, a degree of Bachelor).

Self-reported health status-The 4th NHS contained the following question about self-perceived health: "In general, how do you consider your health status?”. Based on self-reported health status we construct two new categories: good health (very good or good self-reported health status) and poor health (fair, bad or very bad self-reported health status).

Functional limitations and disability-Respondents of the 4th NHS were asked if they have any difficulty or a complete inability in performing a set of tasks. From these questions, three groups of limitations were considered: 1) functional limitations, 2) disabilities in activities of daily living (ADL) and 3) disabilities in instrumental ADL. In the first group, we included the questions related to mobility and to specific physical functional limitations. These included being bedridden or being unable to: go outside the home, walk at least 200 meters or being wheelchair-bound, walk up and down a twelve-step staircase without resting, get into and out of bed, sitting down and getting up from a chair, bend down and lift an object from the floor or grab a small object, alone and without difficulty. In this group, we also considered being unable to listen to a TV or radio show in a reasonable volume, being unable to see in order to recognize a friend at 4 meters of distance or having difficulties with speaking. In the second group, we included the disabilities that show dependence of the individual on others, with need for assistance in daily life. These included being unable to go to the bathroom and use it, get dress and undressed, have bath, wash hands and face or feed him/herself alone, without difficulty. The third group included the disabilities affecting a broader range of activities: being unable to use public transport, to go shopping, to do the housekeeping or to prepare food alone, without difficulty. Each group was considered in the form of a binary variable ( 1 if at least one of the limitations is present and 0 , otherwise).

Additional variables-We worked with individuals aged 45 years and over in the starting year for the demographic projections (2011), since these are the ones with 65 years and more in 2031. Age was categorized into five-year groups until 75+ years.

\subsection{Data Analysis}

A multistate demographic model [16] was used to produce demographic projections by gender, age group and 
educational attainment, at the national level, using discrete matrix equations [17]. The model was based on the cohort component methodology adapted to a multidimensional population. We assumed that no transitions between levels of education would occur in the considered age groups. We considered the existence of differentials regarding fertility, mortality and migration, by level of education. The age- and education-specific survival ratios and fertility rates estimates were disposed into a block Leslie matrix which, together with a vector for net migration, was used to estimate the number of individuals from each gender, age group and education level, by the end of each five-year projection period.

To study the differences in self-reported health status, functional limitations and disability by age and educational level, logistic regression models [18] [13] were separately estimated for each gender. The Dummy variables referring to five-year age groups and levels of education were used as explanatory variables. Both for the variables corresponding to age and educational level, we used a deviation coding scheme, in which the effect of each class is compared to the average effect of all groups [19].

The expected proportions of individuals in each category of the dependent variables, for each gender, age group and educational level, were applied to the estimated number of individuals in each of the strata defined by gender, age group and educational level, obtained from the demographic projections previously described.

\section{Results}

Portuguese population (65+ years) by gender, age group and educational attainment, 2011-2031

The results from the demographic projections suggest an increase in the total number of residents in Portugal aged 65 years and over, rising from 1,931,457 inhabitants in 2011, to 2,226,497, by 2031 (Table 1). According to these projections, the percentage of individuals between 65 and 74 years old among those aged over 65 will increase until 2031 (from 52.6\% to 57.1\%), but the older group (75 years and over) will continue to be the most numerous.

In Figure 1, we see the expected increase in the total number of people aged 65 and over, together with a clear change in its educational structure: by 2031, $40.3 \%$ of individuals in this group should have completed at least Lower Secondary Education, which represents a rise of 26.8 percentage points compared to 2011; on the other hand, the percentage of people with Higher Education, which stood at 4.6\% in 2011, is expected to increase to $13.04 \%$ by 2031 .

Self-reported health status, functional limitations and disability, 2011-2031

The results from the logistic regression models based on data from the 4th NHS (Table 2) suggest that the oldest individuals (aged 75 years and over) have a significantly higher risk of presenting a poor self-reported health status, functional limitations and both types of disabilities, in comparison with the entire group of people with 65 years old and more. In contrast, the group of individuals between 65 and 69 years old show a significantly lower risk of presenting such health outcomes. These differences are clear in both genders.

These results also suggest that the effect of education (adjusted for age) among individuals with 65 years and over is observed in all the considered health outcomes and in both genders, with individuals without Lower Secondary education showing a statistically higher risk of having poor self-perceived health status $(\mathrm{OR}=2.33$; $\mathrm{p}$ $=0.00$ for men and $\mathrm{OR}=3.08 ; \mathrm{p}=0.00$ for women), at least one functional limitation $(\mathrm{OR}=1.78 ; \mathrm{p}=0.01$ for men and $\mathrm{OR}=1.67 ; \mathrm{p}=0.02$ for women), one disability in $\mathrm{ADL}(\mathrm{OR}=2.21 ; \mathrm{p}=0.03$ for men and $\mathrm{OR}=2.71 ; \mathrm{p}$ $=0.01$ for women $)$ or one disability in instrumental ADL $(\mathrm{OR}=2.09 ; \mathrm{p}=0.02$ for men and $\mathrm{OR}=1.98 ; \mathrm{p}=0.01$ for women), compared with the whole population of this age group. Also, individuals with Higher education show a lower risk of reporting their health status as poor $(\mathrm{OR}=0.58 ; \mathrm{p}=0.001$ for men and $\mathrm{OR}=0.56 ; \mathrm{p}=$ 0.002 for women).

Considering the projected prevalence for each of the indicators, and for both genders, the results suggest a clear improvement in all health outcomes (Table 3). The proportion of people with poor self-perceived health status will reduce 5.8 percentage points (pp) for men and $6.7 \mathrm{pp}$ for women. All the other percentages will decrease approximately $2 \mathrm{pp}$.

This improvement tends to be slightly larger for women than for men. Nevertheless, the proportion of individuals who negatively classify their health status, who have some functional limitation and who have some disability will continue to be considerably higher among women, compared to the male residents. Figure 2 shows exactly these differences between genders. 
Table 1. Population structure by gender, age group and level of education, 2011 and 2031, individuals aged 65+ years.

\begin{tabular}{|c|c|c|c|}
\hline & & \multicolumn{2}{|c|}{ Year } \\
\hline & & 2011 & 2031 \\
\hline \multicolumn{2}{|c|}{ Total $\left(\mathbf{N}^{\circ}\right)$} & $1,931,457$ & $2,226,497$ \\
\hline \multirow{2}{*}{ Gender } & $\mathbf{M}$ & $41.7 \%$ & $42.0 \%$ \\
\hline & $\mathbf{F}$ & $58.3 \%$ & $58.0 \%$ \\
\hline \multirow{3}{*}{ Age Group (years) } & $65-69$ & $27.5 \%$ & $31.0 \%$ \\
\hline & $70-74$ & $25.1 \%$ & $26.1 \%$ \\
\hline & $75+$ & $47.4 \%$ & $42.9 \%$ \\
\hline \multirow{4}{*}{ Level of Education } & N.E./Primary & $86.5 \%$ & $59.7 \%$ \\
\hline & Lower Sec. & $5.4 \%$ & $15.1 \%$ \\
\hline & Upper Sec. & $3.6 \%$ & $12.2 \%$ \\
\hline & Higher & $4.6 \%$ & $13.04 \%$ \\
\hline
\end{tabular}

Source: Authors' calculations.

Table 2. Adjusted odds ratios from logistic regressions.

\begin{tabular}{|c|c|c|c|c|c|c|c|c|c|}
\hline \multirow[t]{2}{*}{ Gender } & \multirow[t]{2}{*}{$\begin{array}{l}\text { Age group/Level } \\
\text { of education }\end{array}$} & \multicolumn{2}{|c|}{ Poor health status ${ }^{a}$} & \multicolumn{2}{|c|}{$\begin{array}{c}\text { Functional } \\
\text { limitations }(\geq 1)^{b}\end{array}$} & \multicolumn{2}{|c|}{$\begin{array}{c}\text { Disabilities in ADL } \\
(\geq 1)^{\mathbf{b}}\end{array}$} & \multicolumn{2}{|c|}{$\begin{array}{l}\text { Disabilities in } \\
\text { instrumental ADL } \\
(\geq 1)^{\mathbf{b}}\end{array}$} \\
\hline & & OR & $\mathbf{p}$ & OR & $\mathbf{p}$ & OR & $\mathbf{p}$ & OR & $\mathbf{p}$ \\
\hline \multirow{7}{*}{ Male } & 65 - 69 years & $0.86^{* *}$ & 0.01 & $0.84^{* *}$ & 0.02 & $0.68^{* *}$ & 0.00 & $0.62^{* *}$ & 0.00 \\
\hline & 70 - 74 years & 0.96 & 0.54 & 0.99 & 0.88 & 0.86 & 0.24 & 1.09 & 0.46 \\
\hline & $75+$ years & $1.22^{* *}$ & 0.003 & $1.20^{* *}$ & 0.01 & $1.72^{* *}$ & 0.00 & $1.49^{* *}$ & 0.00 \\
\hline & NE/Primary & $2.33^{* *}$ & 0.00 & $1.78^{* *}$ & 0.01 & $2.21^{* *}$ & 0.03 & $2.09^{* *}$ & 0.02 \\
\hline & Lower Sec. & 0.83 & 0.21 & 0.97 & 0.89 & 0.62 & 0.32 & 0.67 & 0.35 \\
\hline & Upper Sec. & 0.88 & 0.47 & 0.79 & 0.46 & 0.62 & 0.41 & 1.02 & 0.97 \\
\hline & Higher & $0.58^{* *}$ & 0.001 & 0.74 & 0.35 & 1.18 & 0.71 & 0.702 & 0.46 \\
\hline \multirow{7}{*}{ Female } & 65 - 69 years & $0.86^{* *}$ & 0.01 & $0.84^{* *}$ & 0.002 & $0.81^{* *}$ & 0.00 & $0.79^{* *}$ & 0.00 \\
\hline & 70 - 74 years & 0.94 & 0.39 & 0.98 & 0.79 & $0.85^{*}$ & 0.06 & 0.995 & 0.95 \\
\hline & $75+$ years & $1.23^{* *}$ & 0.003 & $1.21^{* *}$ & 0.001 & $1.45^{* *}$ & 0.00 & $1.28^{* *}$ & 0.00 \\
\hline & NE/Primary & $3.08^{* *}$ & 0.00 & $1.67^{* *}$ & 0.02 & $2.71^{* *}$ & 0.01 & $1.98^{* *}$ & 0.01 \\
\hline & Lower Sec. & $0.67^{* *}$ & 0.02 & 1.08 & 0.79 & 0.52 & 0.26 & 0.59 & 0.21 \\
\hline & Upper Sec. & 0.87 & 0.51 & 0.93 & 0.82 & 0.76 & 0.65 & 1.64 & 0.17 \\
\hline & Higher & $0.56^{* *}$ & 0.002 & 0.601 & 0.14 & 0.93 & 0.89 & 0.52 & 0.17 \\
\hline
\end{tabular}

${ }_{\mathrm{a}}^{\mathrm{a}}=6929 ;{ }^{\mathrm{b}} \mathrm{n}=6930 .{ }^{* *} p \leq 0.05 ;{ }^{*} p \leq 0.10$. Source: Authors' calculations.

Table 3. Projected prevalence for each health indicator, by gender, 2011-2031, Portugal.

\begin{tabular}{|c|c|c|c|c|}
\hline & Gender & 2011 & 2021 & 2031 \\
\hline \multirow{2}{*}{ Poor health status } & M & $78.9 \%$ & $76.0 \%$ & $73.1 \%$ \\
\hline & $\mathrm{F}$ & $87.7 \%$ & $84.9 \%$ & $81.0 \%$ \\
\hline \multirow{2}{*}{ Functional limitations $(\geq 1)$} & M & $13.9 \%$ & $12.9 \%$ & $11.8 \%$ \\
\hline & $\mathrm{F}$ & $16.6 \%$ & $15.7 \%$ & $14.4 \%$ \\
\hline \multirow{2}{*}{ Disabilities in ADL $(\geq 1)$} & M & $6.8 \%$ & $6.1 \%$ & $5.4 \%$ \\
\hline & $\mathrm{F}$ & $9.3 \%$ & $8.5 \%$ & $7.4 \%$ \\
\hline \multirow{2}{*}{ Disabilities in instrumental ADL $(\geq 1)$} & M & $7.7 \%$ & $6.9 \%$ & $6.2 \%$ \\
\hline & $\mathrm{F}$ & $11.7 \%$ & $10.9 \%$ & $9.9 \%$ \\
\hline
\end{tabular}

Source: Authors’ calculations. 


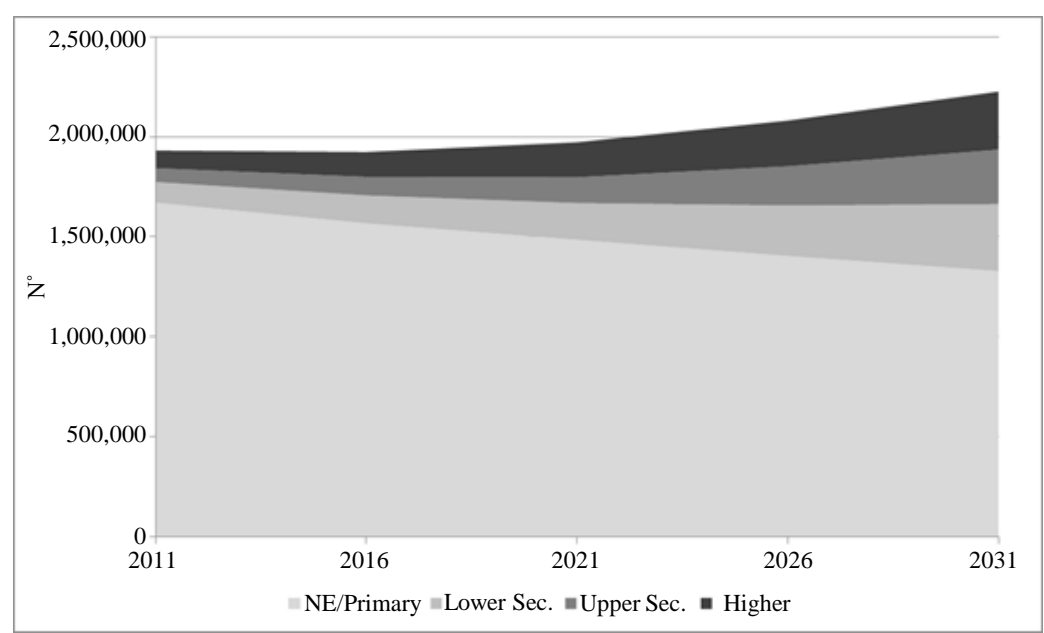

Source: Authors' calculations.

Figure 1. Number of people aged 65+, by level of education, 2011-2031.
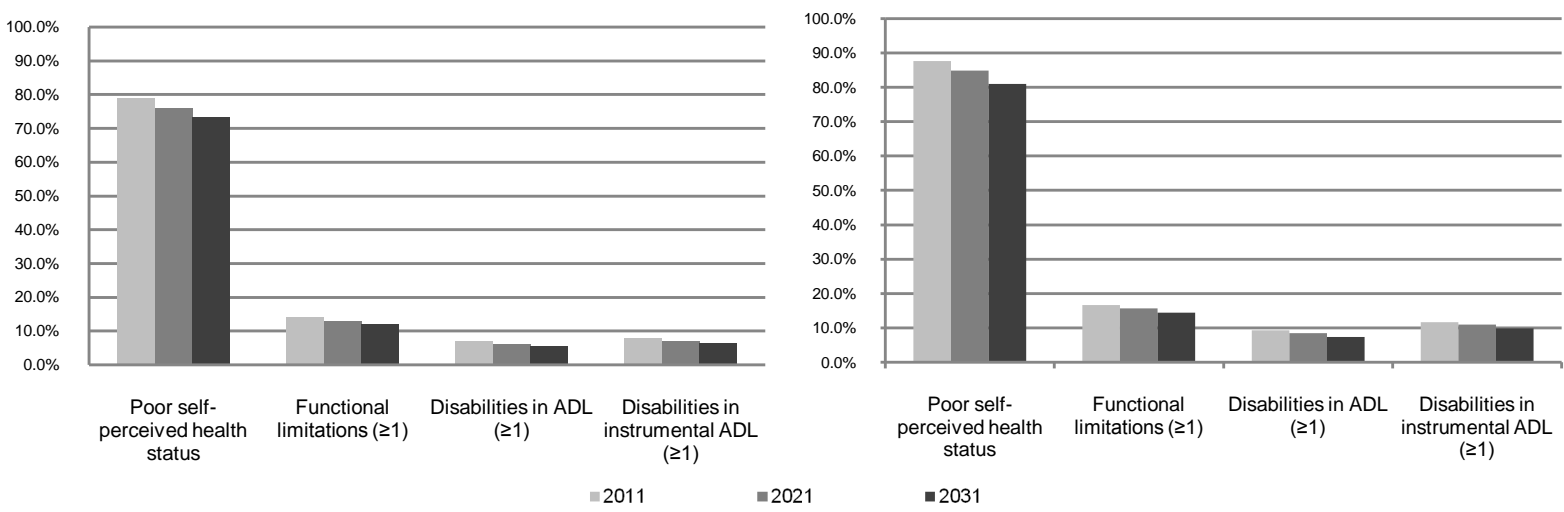

Source: Authors’ calculations.

Figure 2. Projected prevalence for each health indicator, men (left) and women (right), 2011-2031, Portugal.

\section{Discussion}

This paper focuses on challenges and opportunities related to projecting health outcomes for Portuguese ageing population. Demographic projections were produced using the multistate cohort component method. Logistic regression models were fitted to estimate current differences in health outcomes, using data from the Portuguese Health Survey. Such differences were applied to the projection results, in order to project the prevalence of "poor" self-reported health status, functional limitations and disability. It has been observed that the prevalence of "poor" self-reported health status, functional limitations and disability will decrease in both genders, but will continue to be higher among women than among men. It has been shown that beyond age and gender, other determinants of health, like education, should be considered when studying the possible evolution of health outcomes in an ageing population.

Albeit its relevance [20], few studies are published on self-rated health and its correlates for Portuguese elder population. This knowledge is crucial not only to identify socioeconomic factors that may influence self-rated health, but also for health policy priorities purpose [21]. Research for other countries [22] suggested that the main determinants in older men and women include, amongst others, age and educational level, and our results for Portugal are in line with these findings.

To predict health outcome trends in an ageing society, as it is the case for Portugal, it is crucial to know population projections by sex, age and educational level. Projections of health outcomes for the Portuguese population aged 65 years and over, by gender, were produced. Demographic projections by gender, age group and level of education, calculated using the multistate projection model, served as the basis for projecting the expected 
changes on the population self-perceived health status and the prevalence of functional limitations, disabilities in ADL and disabilities in instrumental ADL. In these demographic projections, the differentials regarding fertility, mortality and migration, by level of education, were taken into account. We found that the self-reported health status is the indicator that has the more obvious expected improvement, with a clear decrease in the proportion of residents who rate their health as poor for both genders. The prevalence of functional limitations and disabilities will also decrease, and will continue to be substantially higher among women, compared to men. This pattern of gender differences in health outcomes has also been found in other studies [22].

Our results point to an important idea about the consequences of population ageing: the extent to which changes in key lifestyle factors, such as education, influence health during the life course and particularly during old age, may have a counterbalancing effect upon the greater vulnerability to disability and morbidity associated with the increase in age.

We may assume that, if increased longevity is accompanied by an increase in the number of years lived in good health, aging may not necessarily translate into increased health expenditure. A better health status will, in principle, be reflected in a lower use of health services and can consequently lead to lower health expenditure [23] [24]. Our results point to a future improvement in health status (particularly, in self-reported health status and in the prevalence of functional limitations and long-term disabilities), as the educational structure of the older Portuguese population improves. This is obviously related with the positive effect that the increase in educational attainment has on health, which was also confirmed in this study. However, if such association is to be explained by a greater use of health services by the more educated people, the health expenses might be expected to increase as education rises. In fact, as discussed by [25], the association between having less years of education and the increased intention to consult a doctor, compared to people with more education years (after adjustment for age and gender), is significant in all welfare regimes, except for the Southern (including for Portugal). Therefore, we might question whether, in the coming decades, we may expect the spending in the Health sector to growth, even if the health outcomes improve.

Projecting the health status of a population is a complex and challenging task, given the difficulties associated with the estimation of changes in morbidity and the measurement of health [24]. Thus, the uncertainty associated with the obtained results is evident. Nevertheless, these projections are very useful, since future trends in morbidity and disability rates will be decisive determinants of societies' capacity to deal with the challenges of population ageing [6] and because they can support the study of the possible evolution of public spending and the impact of education and the population health status as the main drivers of health expenditure, supporting the decision making process by the policy makers.

\section{Conclusion}

When dealing with a variable such as education, we have to take into account that the current changes in the schooling rates of the population will only have an influence many years later: the educational structure of people who are expected to reach 65 years and over within two decades is the result of the schooling rates from about 35 to 15 years ago. Considering this, we should try to look into the impact that the present developments in the Education sector might have in a longer term. Until now, we can expect the proportion of people with higher education levels to continue to rise, as the education of younger cohorts seems to evolve positively, but it is still not well understood if this positive development will continue, giving the economic situation that Portugal is currently facing. Moreover, we will expect the better educational levels of the elderly to have an important impact on functional fitness outcomes, enhancing the quality of life of these population, namely within the context of the community physical activity programs that has been recently implemented in the Portuguese society [26].

\section{Acknowledgements}

This work was co-funded by FEDER funds through the Operational Programme for Competitiveness FactorsCOMPETE and by National funds through FCT—Fundação para a Ciência e a Tecnologia as part of the project Aging and Health in Portugal: Policies and Practices, FCOMP-01-0124-FEDER-PTDC/CS-DEM/109967/2009.

\section{References}

[1] OECD (2012) Education at a Glance: OECD Indicators 2012-Country Note Portugal.

[2] OECD (2011) Health Reform: Meeting the Challenge of Ageing and Multiple Morbidities. OECD Publishing. 
[3] Olshansky, S.J. (2012) Leadership: The Elders. Global Population Ageing: Peril or Promise? PGDA Working Papers, Program on the Global Demography of Aging, 42-45.

[4] Parker, M.G. and Thorslund, M. (2007) Health Trends in the Elderly Population: Getting Better and Getting Worse. Gerontologist, 47, 150-158. http://dx.doi.org/10.1093/geront/47.2.150

[5] Orfila, F., Ferrer, M., Lamarca, R. and Alonso, J. (2000) Evolution of Self-Rated Health Status in the Elderly: CrossSectional vs. Longitudinal Estimates. Journal of Clinical Epidemiology, 53, 563-570. http://dx.doi.org/10.1016/S0895-4356(99)00230-9

[6] Christensen, K., Doblhammer, G., Rau, R. and Vaupel, J.W. (2009) Ageing Populations: The Challenges Ahead. The Lancet, 374, 1196-1208. http://dx.doi.org/10.1016/S0140-6736(09)61460-4

[7] Cavelaars, A.E.J.M., Kunst, A.E., Geurts, J.J.M., et al. (1998) Differences in Self-Reported Morbidity by Educational Level: A Comparison of 11 Western European Countries. Journal of Epidemiology \& Community Health, 52, 219-227. http://dx.doi.org/10.1136/jech.52.4.219

[8] Cutler, D.M. and Lleras-Muney, A. (2006) Education and Health: Evaluating Theories and Evidence. National Bureau of Economic Research Working Paper, No. 12352, Cambridge.

[9] Shaw, B.A. and Spokane, L.S. (2008) Examining the Association between Education Level and Physical Activity Changes during Early Old Age. Journal of Aging and Health, 20, 767-787. http://dx.doi.org/10.1177/0898264308321081

[10] Brunello, G., Fort, M., Schneeweis, N. and Winter-Ebmer, R. (2011) The Causal Effect of Education on Health: What Is the Role of Health Behaviors? IZA Discussion Paper, No. 5944, Bonn.

[11] Denton, M., Prusb, S. and Walters, V. (2004) Gender Differences in Health: A Canadian Study of the Psychosocial, Structural and Behavioural Determinants of Health. Social Science \& Medicine, 58, 2585-2600. http://dx.doi.org/10.1016/j.socscimed.2003.09.008

[12] Hoogendijk, E., van Groenou, M.B., van Tilburg, T. and Deeg, D. (2008) Educational Differences in Functional Limitations: Comparisons of 55-65-Year-Olds in the Netherlands in 1992 and 2002. International Journal of Public Health, 53, 281-289.

[13] Joung, I.M.A., Kunst, A.E., Imhoff, E. and Mackenback, J.P. (2000) Education, Aging, and Health: To What Extent Can the Rise in Educational Level Relieve the Future Health Care Burden Associated with Population Aging in the Netherlands? Journal of Clinical Epidemiology, 53, 955-963. http://dx.doi.org/10.1016/S0895-4356(99)00232-2

[14] Huisman, M., Kunst, A.E. and Mackenbach, J.P. (2003) Socioeconomic Inequalities in Morbidity among the Elderly: A European Overview. Social Science \& Medicine, 57, 861-873. http://dx.doi.org/10.1016/S0277-9536(02)00454-9

[15] Henriques, F.C. and Rodrigues, T.F. (2010) Essay on Ageing and Health Projections in Portugal. Item 3-Challenges and Use of Population Projections. Joint Eurostat/UNECE Work Session on Demographic Projections (28-30 April 2010, Lisbon, Portugal), Statistical Office of the European Union (EUROSTAT).

[16] Willekens, F. (2006) Description of the Multistate Projection Model (Multistate Model for Biographic Analysis and Projection). Deliverable D1 in Work Package 1. Bridging the Micro-Macro Gap in Population Forecasting-MicMac Project. Netherlands Interdisciplinary Demographic Institute, The Hague.

[17] Schoen, R. (2006) Population Models with Constant Rates. Dynamic Population Models, Vol. 17, The Springer Series on Demographic Methods and Population Analysis, Springer, The Netherlands, 1-26. http://dx.doi.org/10.1007/1-4020-5230-8_1

[18] Hosmer, D.W. and Lemeshow, S. (2004) Applied Logistic Regression. 2nd Edition, John Wiley \& Sons, New York.

[19] Hair, J.F., Anderson, R.E., Tatham, R.L. and Black, W.C. (1998) Multivariate Data Analysis. Prentice Hall, Upper Saddle River.

[20] French, D.J., Sargent-Cox, K. and Luszcz, M.A. (2012) Correlates of Subjective Health across the Aging Lifespan: Understanding Self-Rated Health in the Oldest Old. Journal of Aging and Health, 24, 1449-1469. http://dx.doi.org/10.1177/0898264312461151

[21] Chen, H., Wang, H., Crimmins, E., Chen, G., Huang, C. and Zheng, X. (2013) The Contributions of Diseases to Disability Burden among the Elderly Population in China. Journal of Aging and Health. http://dx.doi.org/10.1177/0898264313514442

[22] French, D.J., Browning, C., Kendig, H., Luszcz, M.A., Saito, Y., Sargent-Cox, K. and Anstey, K.J. (2012) A Simple Measure with Complex Determinants: Investigation of the Correlates of Self-Rated Health in Older Men and Women from Three Continents. BMC Public Health, 12, 649. http://dx.doi.org/10.1186/1471-2458-12-649

[23] Rechel, B., Doyle, Y., Grundy, E. and McKee, M. (2009) How Can Health Systems Respond to Population Ageing? World Health Organization, Regional Office for Europe, Copenhagen.

[24] European Commission (2012) The 2012 Ageing Report: Economic and Budgetary Projections for the 27 EU Member 
States (2010-2060). European Economy, Brussels.

[25] Frie, K.G., Eikemo, T.A. and von dem Knesebeck, O. (2010) Education and Self-Reported Health Care Seeking Behaviour in European Welfare Regimes: Results from the European Social Survey. International Journal of Public Health, 55, 217-220. http://dx.doi.org/10.1007/s00038-009-0073-3

[26] Marques, A., Rosa M.J., Soares, P., Santos, R., Mota J. and Carvalho, J. (2011) Evaluation of Physical Activity Programmes for Elderly People-A Descriptive Study Using the EFQM’ Criteria.BMC Public Health, 11, 123.

http://dx.doi.org/10.1186/1471-2458-11-123 
Scientific Research Publishing (SCIRP) is one of the largest Open Access journal publishers. It is currently publishing more than 200 open access, online, peer-reviewed journals covering a wide range of academic disciplines. SCIRP serves the worldwide academic communities and contributes to the progress and application of science with its publication.

Other selected journals from SCIRP are listed as below. Submit your manuscript to us via either submit@scirp.org or Online Submission Portal.
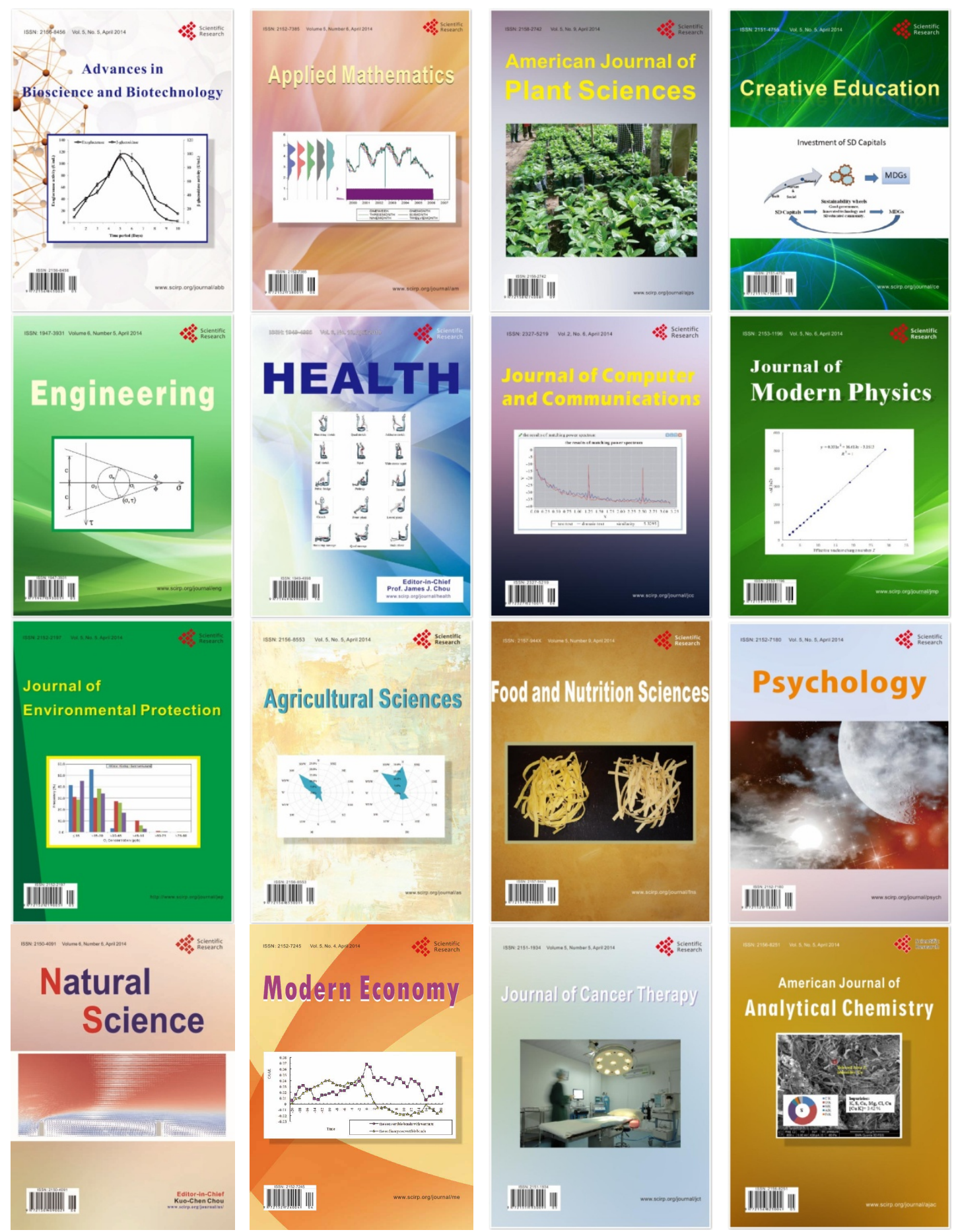